\title{
СИСТЕМА МОНИТОРИНГА СЕЙСМИЧНОСТИ СЕВЕРО-ЗАПАДНОГО РЕГИОНА
}

\section{Аленичева А.О., Прокудина А.В., Федоров И.С.}

Кольский филиал ФИЦ Единая геофизическая служба PAH, Anamumbl, polushkina-alena@ya.ru

Наблюдения за сейсмической активностью Северо-Западного региона ведутся независимо несколькими сейсмологическими организациями. Служба NORSAR (Норвегия) обрабатывает данные ряда сейсмических групп, расположенных на территории Норвегии, Швеции и Финляндии и формирует собственный автоматический бюллетень, доступный через Интернет. В бюллетень входит информация о сейсмических событиях на территории от Норвегии до архипелага Новая Земля. Финский институт сейсмологии производит мониторинг территории Финляндии и примыкающих регионов Швеции, Норвегии и России. Норвежская национальная сейсмологическая сеть NNSN осуществляет наблюдения за сейсмичностью территории Норвегии, Норвежского и Баренцева морей и архипелага Шпицберген. Сейсмические станции Кольского филиала ФИЦ «Единая Геофизическая служба РАН» (далее КоФ ФИЦ ЕГС РАН) регистрирует сейсмические события на Кольском полуострове, северной Карелии и Финляндии, в Баренцевом море и на архипелаге Шпицберген. Кроме того, наиболее сильные события региона регистрируются глобальными сейсмическими сетями. Так, в сеть IRIS (Incorporated Research Institution for Seismology) входят две сейсмические станции региона - Кингсбей (архипелаг Шпицберген) и Ловозеро (Кольский полуостров).

Однако бюллетени отдельных организаций обладают полнотой только для своих территорий уверенного наблюдения. Могут отличаться результаты локации сейсмических событий, оценки их глубин и магнитуд. Поэтому объединение сейсмостанций в единую сеть является необходимым этапом развития сейсмологии в регионе.

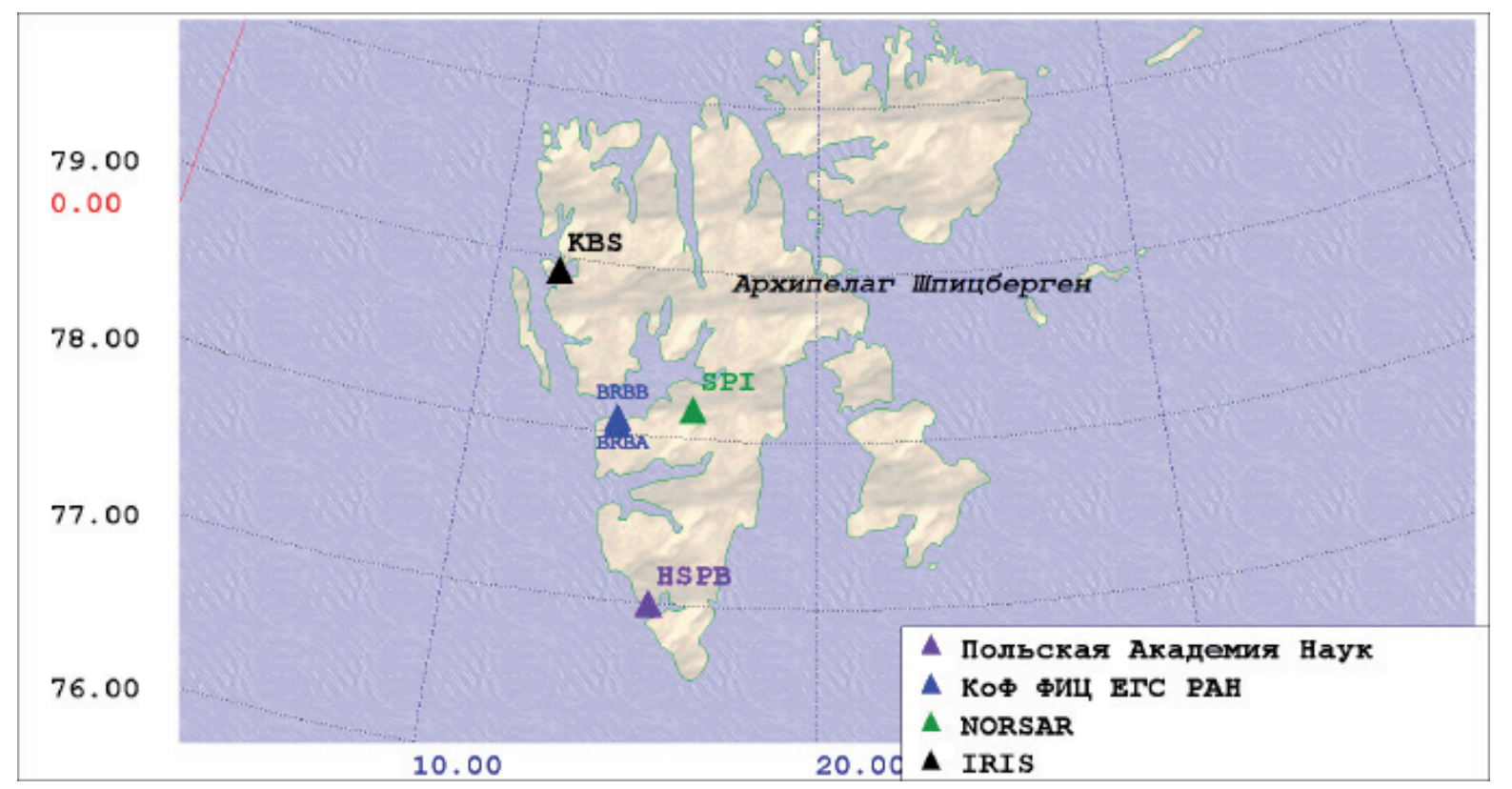

Рис. 1. Сеть станций, используемая в системе автоматического мониторинга.

Подсистема архипелага Шпицберген. 


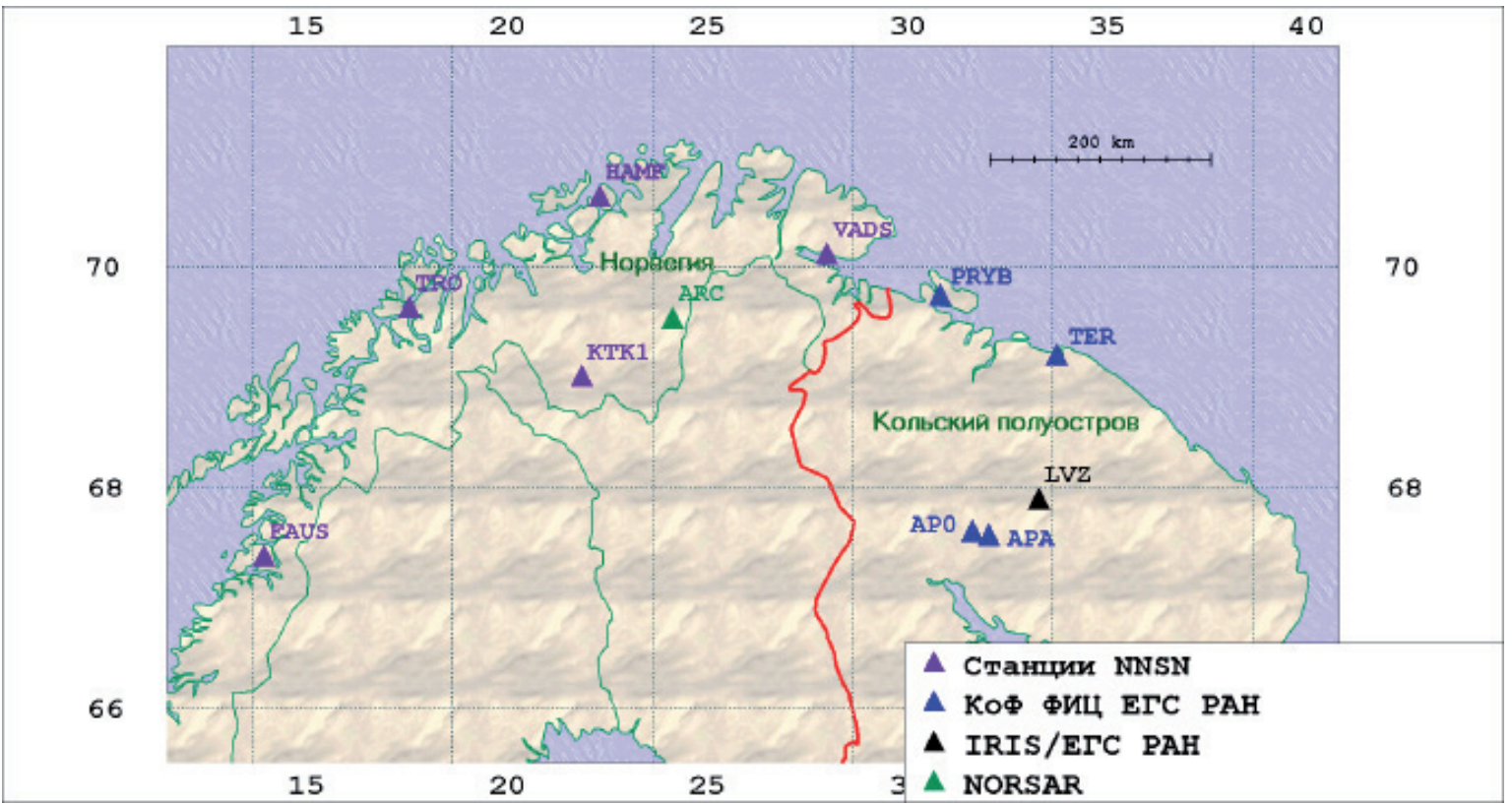

Рис. 2. Сеть станций, используемая в системе автоматического мониторинга. Континентальная подсистема.

Предпосылками к такому объединению явилось развитие телекоммуникационных технологий, а также разработка в КоФ ФИЦ ЕГС РАН в 2014-2015 гг. новой системы автоматического детектирования и локации сейсмических событий NSDL.

В 2015-2016 гг. были организованы потоки сейсмических данных в КоФ ФИЦ ЕГС РАН. Был получен доступ к данным NORSAR (сейсмические группы ARCES и SPI), данным Норвежской национальной сети NNSN, станций IRIS (Кингсбей, Ловозеро). Географически все доступные станции были разбиты на два кластера - материковый и кластер архипелага Шпицберген (рис. 1, 2).

Данные всех станций в реальном времени передаются в центр обработки в г. Апатиты, где производится сначала детектирование сейсмических событий в режиме времени, близком к реальному, по отдельным станциям, а затем результаты ассоциируются по всем станциям кластеров. Формируется оперативный полностью автоматический сейсмический бюллетень, доступный в Интернете на сайте КоФ ФИЦ ЕГС РАН [http://www.krsc.ru/onlinebulletin].

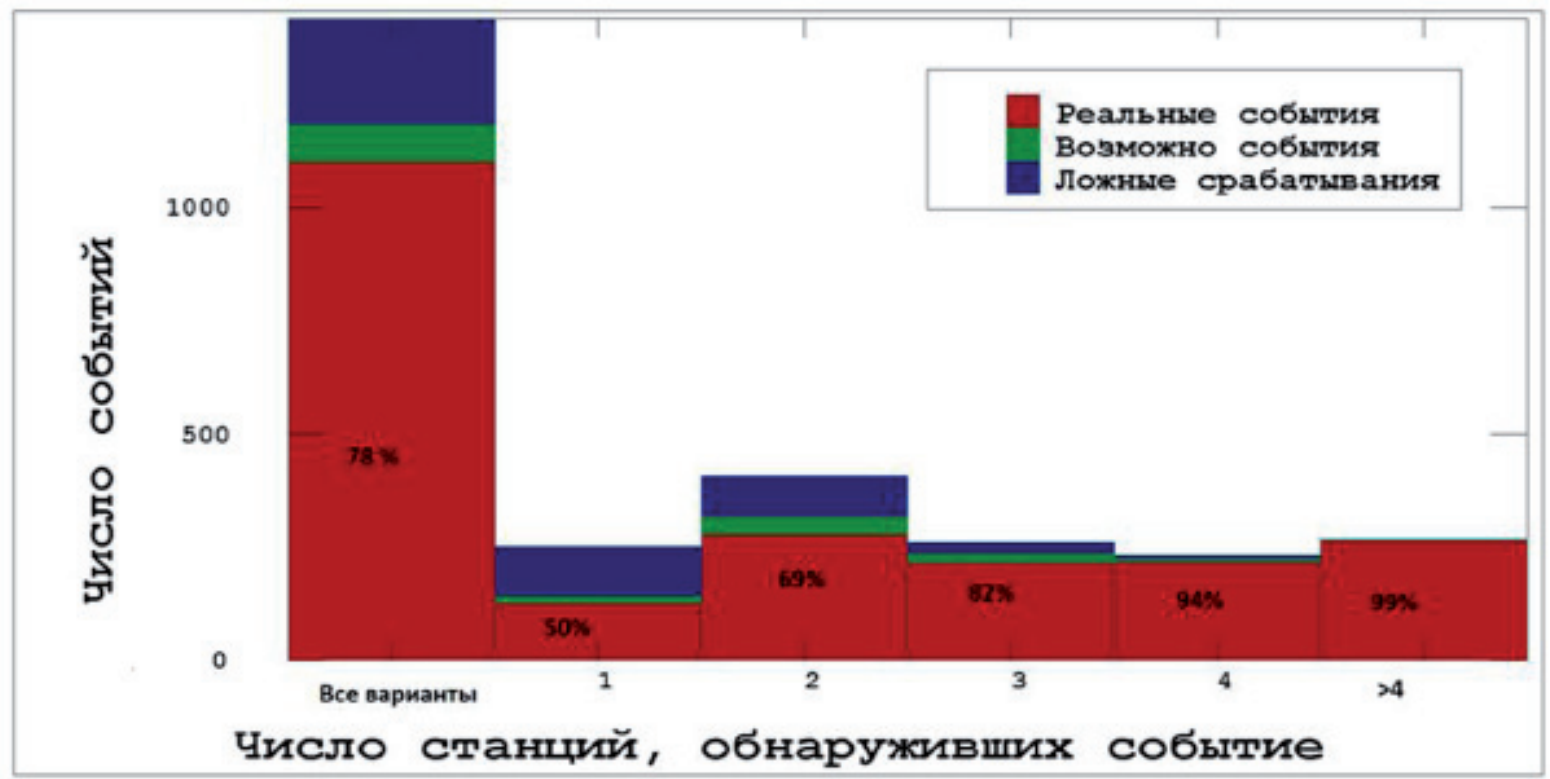

Рис. 3. Статистика срабатываний системы за июнь 2017 г. 


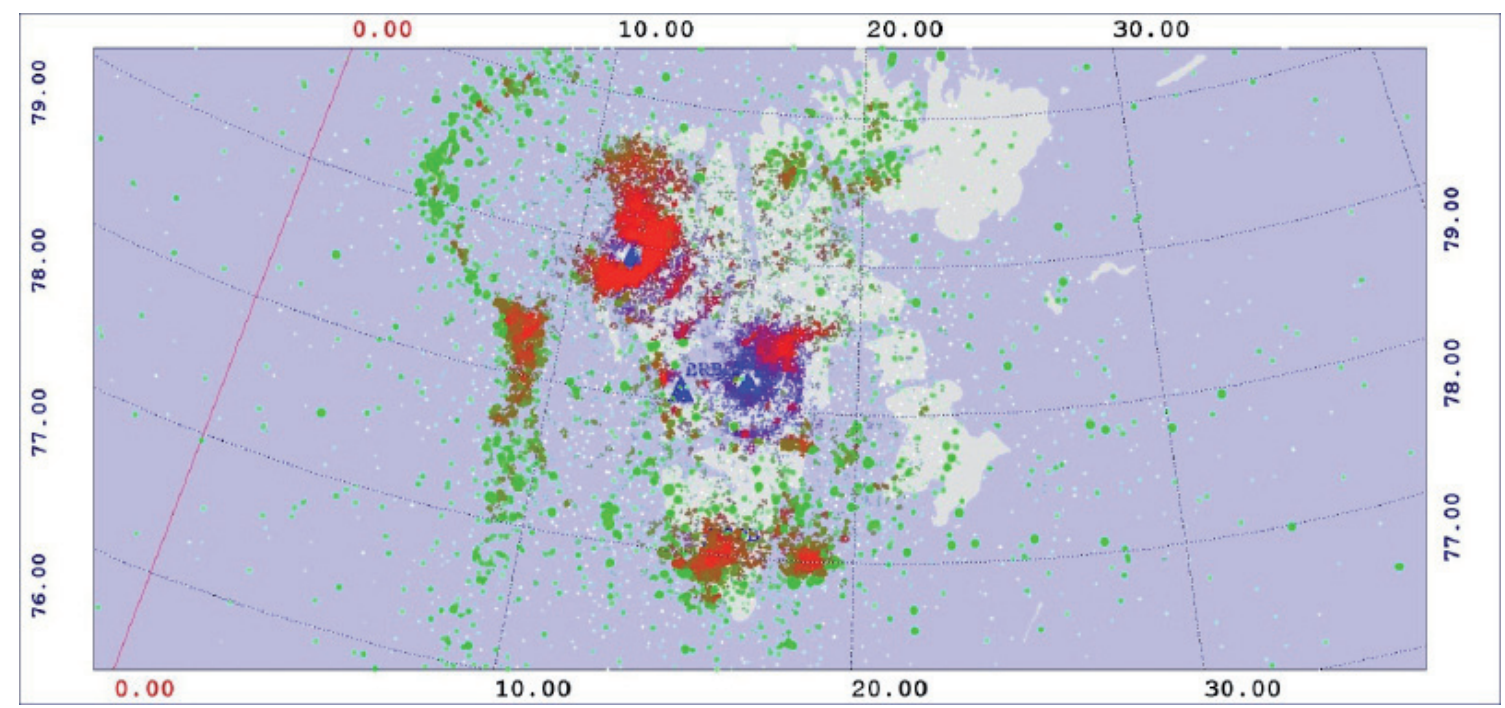

Рис. 4. Результаты работы кластера архипелага Шпицберген за январь-октябрь 2017 г.

Как и все автоматические системы, NSDL иногда ошибается и порождает ложные срабатывания, т.е. выдает информацию о сейсмических событиях, которых на самом деле не было. Большая часть ложных срабатываний происходит при ассоциации данных одной-двух сейсмостанций (рис. 3).

На рис. 3 приведена статистика срабатываний системы (материковый кластер) за один месяц. 78 \% всех срабатываний соответствуют реальным сейсмическим событиям. В случае, если событие обнаружено 4-мя и более сейсмостанциями, оно реально с вероятностью $94 \%$.

Для генерации окончательного сейсмического бюллетеня результаты работы автоматической системы просматриваются человеком, который отбраковывает ложные срабатывания и исправляет ошибки локации.

Высокий процент реальных событий позволяет использовать автоматический бюллетень в статистических целях без пост-обработки человеком. Так, по результатам работы Шпицбергенского кластера станций (рис. 4) за январь-октябрь 2017 г. было зарегистрировано свыше 30000 сейсмических событий, получена детальная картина сейсмичности архипелага и ее изменений во времени. Ручная проверка данных показала, что число ложных срабатываний не превысило 10-15 \% [1].

На рис. 4 хорошо видно насколько архипелаг Шпицберген сейсмически активен. В результате работы системы выделены зоны повышенной активности, не только характерные для сейсмического режима данной территории, но и требующие дополнительного наблюдения и изучения.

На текущем этапе эволюционного развития сейсмологии на территории Северо-Западного региона возникает необходимость в формировании единой сети сейсмостанций для мониторинга Арктической зоны. Автоматическая система мониторинга NSDL позволяет с более высокой точностью обнаруживать и лоцировать сейсмические события без участия интерпретатора.

\section{Литература}

1. Асминг В.Э., Федоров А.В., Евтюгина 3.А., Аленичева А.О. Применение системы автоматической локации NSDL для детального изучения сейсмичности архипелага Шпицберген // Вестник МГТУ, Мурманск, 2018. Т. 21. № 1.

2. Фёдоров А.В., Асминг В.Э., Евтюгина 3.А., Прокудина А.В. Система автоматического мониторинга сейсмичности Европейской Арктики Сейсмические приборы. 2018. Т. 54. № 1. С. 1-8. 